\title{
Negative equity companies in Europe: theory and evidence
}

\author{
Sara Urionabarrenetxea ${ }^{1}$, Leire San-Jose ${ }^{1,2}$, Jose-Luis Retolaza ${ }^{3}$ \\ 1 Department of Financial Economics II, Ethics in Finance and Social Value, University of the Basque Country UPV/EHU, Lehendakari Aguirre \\ 83-48015, Bilbao, Biscay, Spain \\ 2 University of Huddersfield, Queensgate, Huddersfield, UK \\ 3 Deusto Business School, ECRI Ethics in Finance and Social Value, Hermanos Agirre, Bilbao, Biscay, Spain
}

Corresponding author: Leire San-Jose (leire.sanjose@ehu.eus)

Received 15 September 2015

Accepted 13 March 2016

Published 10 November 2016

Academic editor:

Živilè Tunčikiené

\section{Keywords}

moral hazard

negative equity

stakeholders

Amadeus

zombies

crisis

\section{JEL Classification}

\begin{abstract}
Businesses in technical bankruptcy are part of the European context, many of them in such financial distress that they have lost all their equity and a very high percentage of them have even incurred negative equity. There is a very little literature analysing these companies; moreover, they are considered as out of the ordinary because they do not fit into conventional theories of business, and are removed from most samples. They are largely neglected. The research questions posed here are a step towards remedying this: "What are the scale and the economic impact of negative equity companies in terms of risk transference?", "Does this problem differ from one European country to another?", "Is it an effect of the crisis?".

Using the Bureau Van Dijk's Amadeus database, we find that nearly 20\% of companies have negative equity. Such companies handle more than one billion Euros, i.e. nearly $10 \%$ of European GDP. So the results suggest that negative equity companies have a high weight in Europe and, based on the country cluster studied, it seems that neither culture nor geographical area is determinant in explaining their distribution across countries. Nor is the crisis a determinant in explaining their existence, so the problem is not cyclical but structural.

These findings have potentially important implications in encouraging European decision makers to factor such companies into their policies and to include them in economic models.
\end{abstract}

\section{Introduction}

The world's leading economies are striving to become more competitive so that they can all get onto the path of sustainable growth and into a new economic cycle. A competitive economy needs a competitive fabric of business, and it is precisely in this aspect that the main weakness of many countries may lie. There are companies whose future viability is uncertain and whose ability to compete is highly limited. These companies may transfer risks, and thus losses should they go under, to others with which they maintain trading and other links. They have in fact been described as "zombie companies" (Ahearne and Shinada 2005; Caballero et al. 2008).

The most extreme type of zombie company comprises negative equity companies which continue to trade in spite of having lost all their equity (see Mohrman and Stuerke 2014 for an example). The risk posed by these extremely leveraged companies lines not so much in the risk of their going bankrupt but rather in the potential economic impact of all their risks being transferred to other companies. Despite the fact that negative equity companies are part of the national context in European countries, scholars of international finance have paid scant attention to them (Luo et al. 2015; Retolaza et al. 2016). The research questions posed here are a step towards remedying this: "What are the scale and the economic impact of negative equity companies in terms of risk transference?" "Does this problem differ from one European country to another?" "Is it an effect of the crisis?".

\section{Research question and structure}

To answer these questions our study uses the Bureau Van Dijk's Amadeus database to analyze the situation in the European Union in 2012 and the Amadeus Top 250,000 database to test for a country effect and a crisis effect and 
to analyse the trend over the 4-year period from 2009 to 2012. Earlier studies have also used these data and the quality of the information in Amadeus has been checked for accounting data (e.g. Faccio et al. 2011). We focus on European countries because reporting requirements and practices mean that rich data are available for a large fraction, in terms of euro value, of the universe of equity.

The aim of this study is to add to the established literature by looking at extremely leveraged companies, with negative equity understood as the worst capital structure of companies in terms of guarantees of meeting the obligations acquired with their stakeholders. This paper demonstrates that the economic impact is potentially high, so an independent study of these companies is needed. We focus our study on the economic viewpoint, in a European analysis based on number of companies and volume of negative equity data, country differentiation and crisis effect.

This paper contributes in three different ways to the literature on the zombie economy in the European Union. First of all, unlike previous studies, our sample includes data on companies from 2009 to 2012, i.e. data covering the period of financial crisis which has increased pressure on companies to operate more efficiently, at least in theory. Secondly, previous studies of this type have focused mostly on the zombie situation (e.g. Caballero et al. 2008), but we look at a different, more extreme situation: negative equity companies. Thirdly, the EU provides information different from that of other studies based only on one country or group of countries. It is thus possible to describe the dimension of the problem as a whole, at least in the European Union. Hence, the results obtained have potentially important implications as regards encouraging European commissions to take into account the scale of negative equity firms. In fact, a country level analysis does not suggest that it is the economically weaker countries in Europe or those with lower economic ratios which have most companies in this extreme situation. The largest companies could be the riskiest ones. Nor is it possible to confirm that the crisis is the main reason for the existence of negative equity companies: this denotes a structural problem. This might contribute to European concerns about the risk assumed because of the lack of enforcement of laws to establish and strengthen practices regarding risks assumed by stakeholders without their awareness and hence without their approval.

This paper is organised as follows. Section 2 discusses the theoretical foundations. Section 3 examines the ways in which negative equity firms may harm the whole economy. Section 4 uses the Amadeus database for 2012 to present the scale of negative equity firms across Europe, showing whether the number of companies in this situation and the volume of negative equity are significant in the European Union. Section 5 examines whether there is a different pattern across Europe using the same database but for 2009-2012. Section 6 seeks to answer the question of whether the problem is related to the crisis or is structural. The paper ends with an outline of the main conclusions drawn and suggestions for future research.

\section{Theoretical foundations}

Negative equity companies are part of the group of socalled "zombie firms": highly inefficient, debt-ridden companies with very low or even negative productivity (Caballero et al. 2008). As Kane (2012: 3) states, "an institution becomes economically insolvent when it sustains losses that drive the realistic value of its assets below the value of its liabilities. A zombie institution is a deeply insolvent firm that continues to operate [...]". One of the main features of firms of this type is that they are highly leveraged (Papworth 2013). The firms with negative equity considered here form part of that group because they are extremely leveraged.

Firms that incur negative equity have lost their entire net worth after years of financial losses; in theory they should go into bankruptcy, since they no longer have any resources to cover the liabilities, but instead they continue doing business. The book value of the assets does not correspond to their market value in many cases, being possible to be significantly higher mainly due to the value of intangibles. Nevertheless, the value of intangibles is not strippable and it is usually attached to the rest of the company, i.e., its value is conditional on the continuation of the business. If moral hazard materialise, the value of these assets could depreciate between $50 \%$ and $70 \%$ (Shleifer and Vishny 1992; Recio 2011). Thus, we consider the book value as correct proxy measure for the present case.

This has two main implications: on the one hand, assets cannot cover liabilities so if the company ceases trading it is impossible for it to meet its financial commitments to third parties; on the other hand, the principle of balance between risk and decision-making is breached and shareholders in the company hold decision rights with no risk relative to capital, as the capital with which the company is operating comprises only borrowing.

Traditional theory of the firm (Coase 1937; Friedman 1962; Williamson 1967; Jensen and Meckling 1976; Demsetz 1983) cannot serve as the theoretical framework for negative equity companies. They put financial objectives designed for shareholders before any other sort of considerations or responsibilities, since capital is the only factor that assumes any residual risk in the context of a business project. According to this approach, maximising shareholder equity is the main objective of any company and all other commitments to creditors are regulated by contract. The company therefore decides the level of risk to be undertaken in operating its business: if it goes well shareholders' equity will increase but if it goes badly equity will probably decrease. Commitments to stakeholders other than shareholders are regulated by contract in all companies.

The case analysed here - companies with negative equity - is particularly difficult to understand from the perspective of conventional theory of the firm, since shareholders' wealth is negative and the company only invests borrowed funds. On the one hand there is no residual risk to shareholders, as there is no real capital, and 
on the other hand the decision-maker is aware that the company has no resources with which to meet contractual payment obligations, so contract performance depends on the smooth running of cash flow generation. We have done a prediction that those companies with positive cash flow in general terms they will recover the positive equity in approximately a month. It is just in average using a relative analysis. Actually the contractual relationship becomes a residual risk relationship because the execution of the contract is not guaranteed but depends on the future of the company. Under these conditions stakeholder theory from the ontological perspective (Retolaza et al. 2014) may clearly be a better interpretative framework.

Stakeholder theory (Freeman 1984; Donaldson and Preston 1995; Jones 1995; Mitchell et al. 1997; Freeman et al. 2008, 2010) holds that apart from its shareholders a company has a number of stakeholder groups whose interests and risks are linked to its good or bad performance. Stakeholders are classically defined as "any group or individual who can affect or is affected by the achievement of the organisation's objectives" (Freeman 1984: 46) and are taken to include at least shareholders, employees, customers, suppliers and society. So the company is managed based on the best interests of stakeholders and not just those shareholders, so that the value that it generates is distributed among all stakeholders.

This approach (Stoney and Winstanley 2001; Agle and Agle 2007) highlights the responsibility of the decision-maker to third parties. If the decision maker is the shareholders or a third party to whom the shareholders have delegated the management of their interests, as is usually the case, he or she must respond in a balanced way to the different interests of all stakeholders (Freeman 1984; Freeman et al. 2010), regardless of whether they are of fiduciary in nature, as in the case of shareholders, or non fiduciary (Boatright 2013), as in cases of contractual relationships.

\section{How could the existence of companies with negative equity affect the economy as a whole?}

It might be thought that while these firms manage to maintain their activity and keep dodging bankruptcy they do not imply any risk for the economy, but regardless of the cash flows a company can generate so as not to go into bankruptcy, the truth is that in a static situation it could not meet its commitments. This is a clear risk to third parties, which will incur losses in case of bankruptcy.

Caballero et al. (2008) study the case of Japan, which has been trying to reactivate its economy for 20 years without obtaining satisfactory results. They analyse the possible consequences for the economy of the non-bankruptcy of zombie companies. On the one hand such companies cause atrophy in economic development, because they prevent the entry and consolidation on the market of potentially efficient companies (Ahearne and Shinada 2005), and on the other hand job creation is very low in areas with a significant proportion of zombie companies, job destruction is greater and productivity levels are lower. Moreover, an increase in the number of zombie companies depresses investment and employment growth in non zombie companies and widens the productivity gap between the two types of company. According to Caballero et al. (2008) the congestion created by zombie companies reduces profits at healthy companies, which discourages entrepreneurship and new investments.

But why do zombie companies have such a great effect on the health of other companies in their sector? Risk transference is a factor that may go along way towards explaining the harm that zombies do to the economy as a whole. This issue has been widely studied in the banking sector with regard to credit risk (BIS 2003; Allen and Carletti 2006; Wagner and Marsh 2006), but it has been sadly neglected in other sectors. Risk transference in banking may be justified in terms of diversification of risks, making it a potential instrument for favouring economic stability, but such arguments are hard to sustain in other sectors. In negative equity firms shareholders have nothing to lose, since the value of their shares is negative, so the company has every incentive to take very risky positions and behave opportunistically (Kane 2012). If the risks materialise, the situation of shareholders would not worsen, since they start from a position of negative equity. Losses will be attributed to third parties, i.e. risks and losses are transferred from companies with negative equity to other, viable firms with which they have economic commitments.

This transference of risks may erode more competitive economies if it takes place in a covert fashion, because its impact on the economy is not known until the risks actually materialise. To date there is no indicator that measures the risk transferred by a company to other companies, to society or to the public administration with which it has contractual relationships.

Risk transference must be studied not just in terms of economic competitiveness but also from an ethical perspective, as it is associated with what is known as "moral hazard": any situation in which one person makes the decision about how much risk to take, while someone else bears the cost if things go badly (Krugman 2009). Moral hazard occurs at negative equity companies more clearly than in any other case, as the shareholders - who still have the right to make decisions - have no capital available to them.

Moral hazard is seen as a manifestation of asymmetric information (Arrow 1971; Pauly 1974; Rowell and Connelly 2012) and it arises in a principal/agent problem. In companies with negative equity the power to make decisions continues to lie with shareholders or with a third party to whom the shareholders have delegated the management of their interests, even though the company has lost all its net worth. As the Agent, the decision-maker should keep his/her interests aligned with those of the 
other stakeholders (the Principal), but this may be extremely difficult in such companies because the shareholders have every incentive to adopt high-risk positions or even act opportunistically, given that they have nothing to lose (Hendrikse 2003), while creditors, who provide all the funds invested by the company, cannot exercise any control over the decisions made at the company because their relationship with it is purely contractual. However, for practical purposes that contractual relationship has become a relationship of residual risk, because fulfilment of the contract is by no means assured: it depends rather on the generation of future cash flow by the company.

Negative equity companies are therefore causing a problem of moral hazard that can affect third parties which have a limited capacity for discernment.

\section{How significant is the existence of negative equity companies across the European Union?}

To work out the extent of the problem of negative equity companies and test whether that problem is anecdotal or may have a significant impact on the economy, we use two variables in absolute and relative terms: the number of companies with negative equity (as a proportion of the total number of companies) and the volume of negative equity (as a proportion of total equity).

The Amadeus database gives us a tool for demonstrating the extent of the problem of companies with negative equity in the European Union. An analysis of the data for 2012 shows that nearly $20 \%$ of companies have negative equity. This means that $3.83 \%$ of total equity is in the form of risky assets, i.e. a total amount of more than 1 billion Euros.

Size is expected to be a determinant criterion because $91 \%$ of all companies with negative equity are small, $7.8 \%$ are medium and $1.2 \%$ are large (see Fig. 1). However, a closer look at the volume of equity of each company reveals that the Pareto Principle is fulfilled: $10 \%$ of companies account for $80 \%$ of the negative equity, which means that the larger a company is, the more negative equity it has. Specifically, small companies are more numerous but the volume of their negative equity is relatively low. Large and medium-sized companies between them account for 0.9 billion Euros in negative equity, and large companies alone for 0.45 billion. This means that the $1.2 \%$ of large companies account for $39 \%$ of the total negative equity, the $7.8 \%$ of medium-sized companies account for a further $39 \%$ and the $91 \%$ of small companies account for just $22 \%$. Small companies are thus much more numerous, their individual impact is low compared to large ones. This suggests that some effort should be made to control the risks taken by third parties in large companies, or at least to inform about potential losses.

The macroeconomic view is also relevant in establishing the scale of the problem. The determinant used is Gross Domestic Product (GDP) because the ratio of negative equity volume to GDP shows the magnitude of the problem at European level. Thus, the scale of the problem in terms of country growth is significant because the European sample of companies with negative equity used in this paper amounts to $6.22 \%$ of GDP. Indeed, using Gross Capital Formation the figure increases to $31.73 \%$. An approximation to the population shows that it borders on $70 \%$ of GDI. Thus, these data suggest that European growth at stake in this hazard problem not only because of the number of companies involved but also because of the millions of Euros that are conditional on the operation of companies in this financial situation. In the worst-case scenario in which all these companies close down together the downturn in EU GDP can be estimated at 1/10.

\section{Does the pattern differ across Europe?}

Another key issue to be solved about negative equity companies is whether the extent of and trend in the problem are similar across European countries or differ from one to another.

Figure 2 shows the trend from 2009 to 2012 in the countries where the percentage of companies with negative equity (NE) is above average $(6 \%)$ and those where

\section{\% Companies NE}

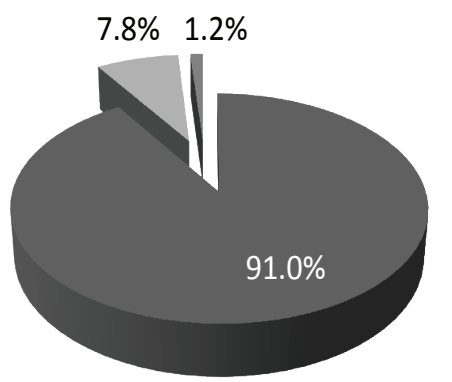

- Small

Medium

Large

\section{$\%$ Volume NE}

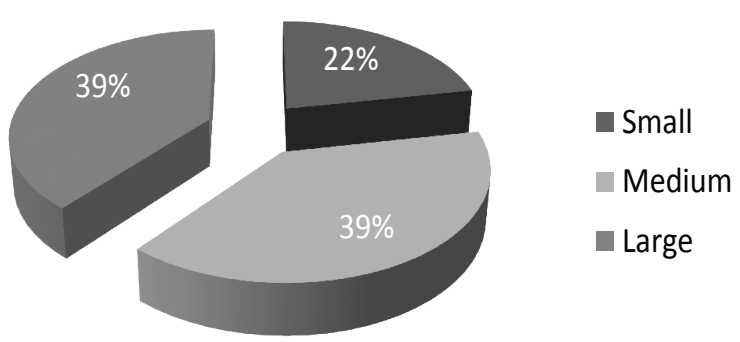

Figure 1. Percentage of companies with negative equity and percentage of negative equity (NE) volume: size criterion (source: own elaboration). 


\section{Number of companies with NE}

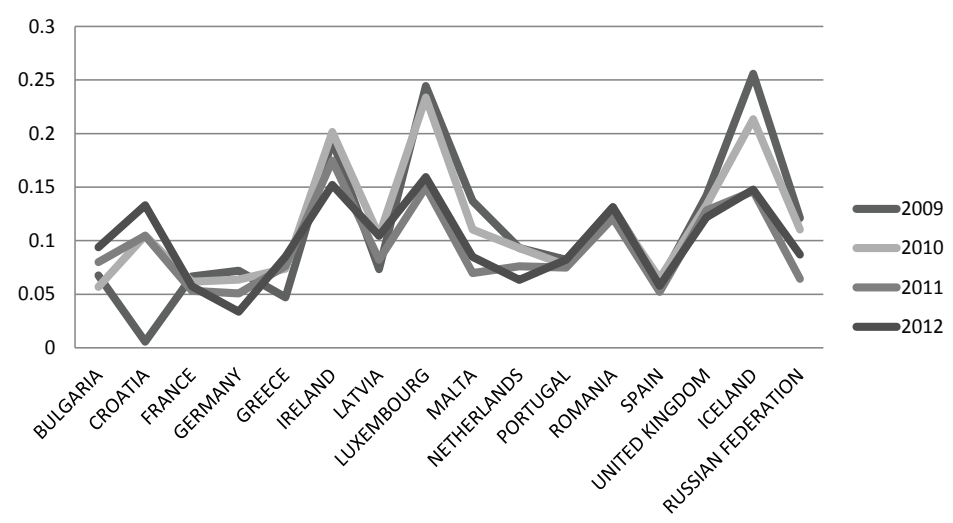

Volume of NE

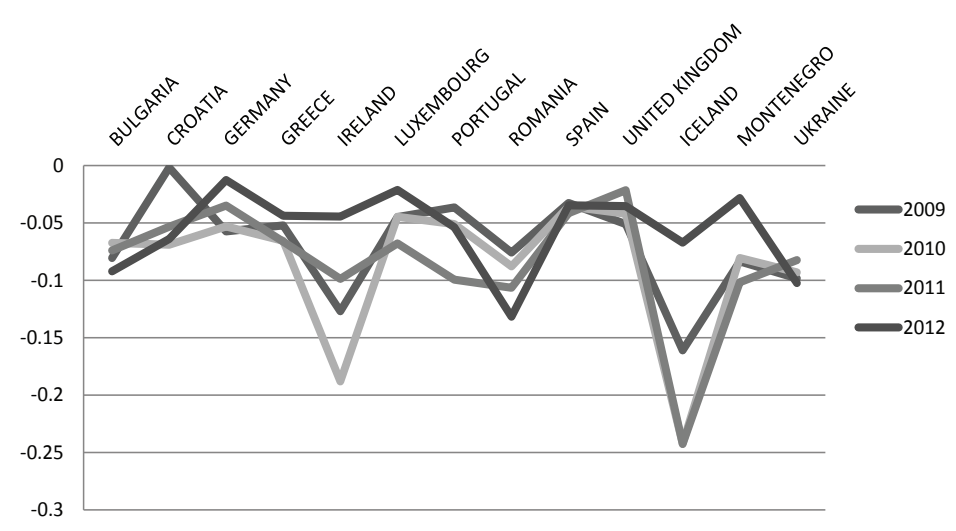

Figure 2. Countries with the highest percentage of companies with negative equity and negative equity volume (source: own elaboration).

the percentage of negative equity volume was above average $(3 \%)$.

Figure 2 illustrates that the situation differs significantly from one country to another. The percentages of negative equity vary widely, and are as high as $25 \%$ in some cases. The percentages of negative equity range between $0 \%$ in Austria and Switzerland and $24 \%$ in Iceland in 2010 and 2011. The two graphs do not refer to the same countries so the two variables considered do not show the same behaviour, i.e. the existence of a large number of companies with negative equity does not necessarily mean that a country has a high volume of negative equity and vice versa.

Given the diversity shown by the data, we have carried out a cluster analysis to identify groups with similar behaviour based on the two criteria used throughout the paper (see Fig. 3), i.e. the number of companies with negative equity and the volume of the negative equity of each country. Out of the three basic approaches to identifying appropriate clustering variables (Ketchen and Shook 1996) we chose the cognitive-deductive approach for a rigorous selection of the criteria used, but the inductive approach for the classification of observations on an exploratory basis. Thus, the number and nature of the resulting groups are closely linked to deductive theory, but not the clustering variables. "High correlation among clustering variables can be problematic because it may overweight one or more underlying construct" (Ketchen and Shook 1996: 444).

Figure 3 shows the position of each country in 2012 according to the number of firms with negative equity and the volume of that equity.

With these results, European countries can be grouped into three clusters referred to here as Low Moral Hazard impact countries (LMH), Medium Moral Hazard impact countries (MMH) and High Moral Hazard impact countries $(\mathrm{HMH})$. The first cluster, which groups the countries with the lowest impact, can itself be split into two subgroups according to the criteria set. Some countries seem to show a similar behaviour pattern: the socioeconomic characteristics of each country and their political and economic decisions may possibly be affecting this. In order to give some explanation to the cluster, we reviewed whether the country clusters made and accepted previously were consistent with this grouping. Unfortunately the cultural clusters (Gupta et al. 2002), for instance, do not match our clusters. It is observed that all the Nordic countries are in the LMH cluster; however Sweden is on the first level but the rest are on the second level. Latin 


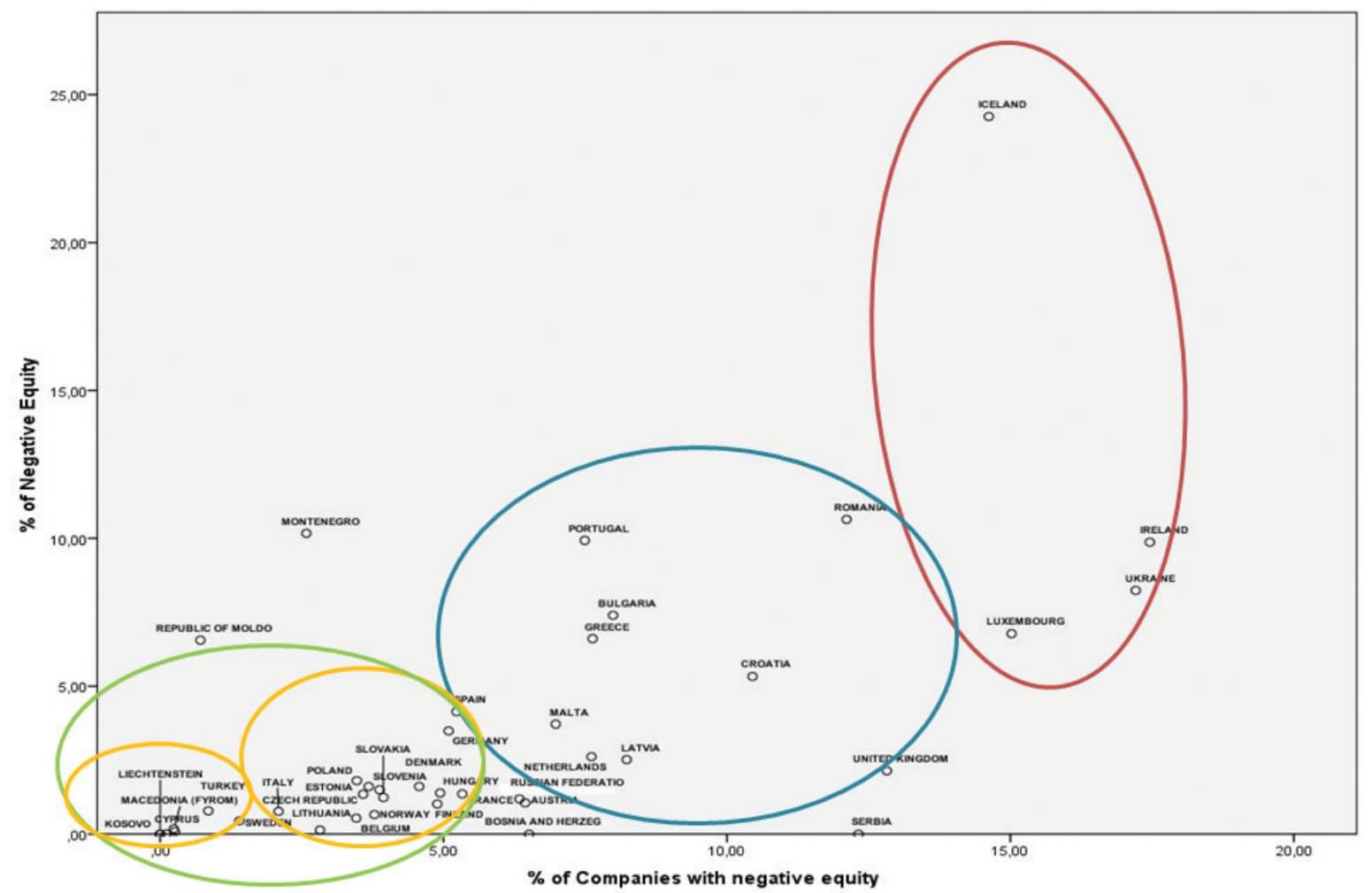

Figure 3. Cluster and Plot Analysis: country determinant (source: own elaboration).

countries can be found in both LMH and MMH, but 75\% of them are in the lowest risk cluster. Although the Latin countries (Spain, Italy and Portugal, for example) are thought to bear or transfer higher risks, this expectation is not borne out by our observations. The Anglo cultures are not in the lowest cluster but in the medium one. The $\mathrm{HMH}$ cluster comprises Luxemburg, Iceland, Ireland and Ukraine. Some countries are not classified because there are no correlations with companies elsewhere. Using another type of clustering, for example geographical clustering, the HMH countries are all from Western Europe but not all Western European countries have high moral hazard. Northern European companies are considered as well developed in terms of performance measures (Kald and Nilsson 2000); in our analysis they are distributed across all three clusters: Sweden, Norway, Lithuania, Finland and Denmark in the LMH cluster, Latvia in the $\mathrm{MMH}$ and Iceland in the HMH. Again, prior expectations about moral hazard behaviour are not totally consistent with previous clustering studies. In short, this exploratory analysis highlights that factors not covered by previous studies could determine the clustering of countries based on negative equity companies, affecting not only economic restructuring but also legal agreements.

Surprisingly not only does the situation differ from one European country to another but so does its evolution during the crisis period.

\section{Is this problem related to the crisis?}

As stated by Papworth (2013: 27), "zombie firms are created by the business cycle", among other causes. A severe cyclical downturn has been noted as a cause of the existence of firms in an extreme financial situation; business risks worsen in times of crisis due to obvious factors. It is common in times of deep crisis, such as the period analysed, for companies that previously obtained positive results to become negative. In many cases in the current crisis these losses, magnified by leverage, have begun to be recurrent and some companies, after years of losses on their income statements, have an extremely high level of leverage or even in some cases have lost all their equity and must face a negative equity situation.

In addition to the crisis itself, the way in which the authorities and banks respond to it can also help create zombie firms. Efforts made by policymakers to avoid "unnecessary" bankruptcies and to "protect jobs" may lead to a proliferation of firms with uncertain future viability (Papworth 2013). Monetary loosening is commonly applied to keep companies which have a viable long-term future in business while demand is temporarily weak (Giles 2013). However, this can also help keep zombie firms alive. Such firms can generate enough revenue to pay the interest on their debts but are unable to bring down the capital amount that they owe. In fact, Stewart (2014), Deloitte's Chief Economist in the UK, defines zombies based on 
low interest rates and the benevolent attitude of banks as "weak, possibly loss making companies, which are able to survive thanks to low interest rates and a supposedly more tolerant attitude to corporate borrowers on the part of banks". During the boom period, banks are keen to expand their loan portfolios as much as possible, so it is easy to create a credit boom and to finance investment projects without properly assessing their risk and viability.

Nevertheless, the current crisis has shown that financial institutions have proven reluctant to drive uncreditworthy borrowers into bankruptcy. Banks would normally be expected to withdraw credit from poorly performing firms, putting pressure on such firms to improve efficiency or close down. Credit would then be reallocated to more productive uses (Ahearne and Shinada 2005). However, this has not occurred in the crisis that began in 2007 (Papworth 2013): indeed rather than withdrawing credit from poorly performing firms, financial institutions are continuing to roll over bad debts, to lend to distressed companies at favourable terms rather than force them into liquidation.

Many companies that are in trouble during a downturn could return to profitability when the recovery comes, so they should not be considered as zombies. In fact, they need to survive to act as the drivers of the recovery once the economy has been restructured. But many others have no future viability and it is imperative to differentiate between the two. The first type of company is closely linked to economic situation, while the second one shows structural problems that will not disappear after the downturn. However, it is difficult to establish an objective measurement scale that would allow it to set a clear boundary between the two types.

One might think of several reasons to relate the proliferation of zombie companies with a downturn cycle. But is that link confirmed in real life? Is it a temporary problem that will tend to disappear when the crisis ends or is it a structural problem that is likely to persist in time, regardless of whether its evolution may have some correlation with the current crisis?

In the following Figures 4 and 5 the two variables used to test for the presence of negative equity firms are shown.

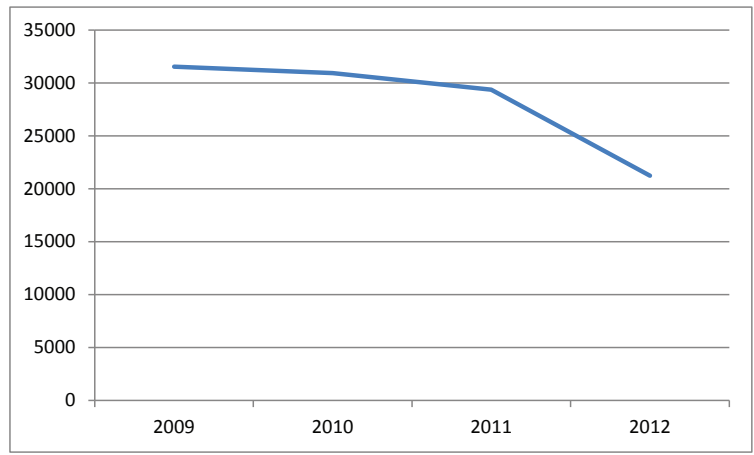

Figure 4. Number of firms with negative equity: 2009-2012 (source: own elaboration).

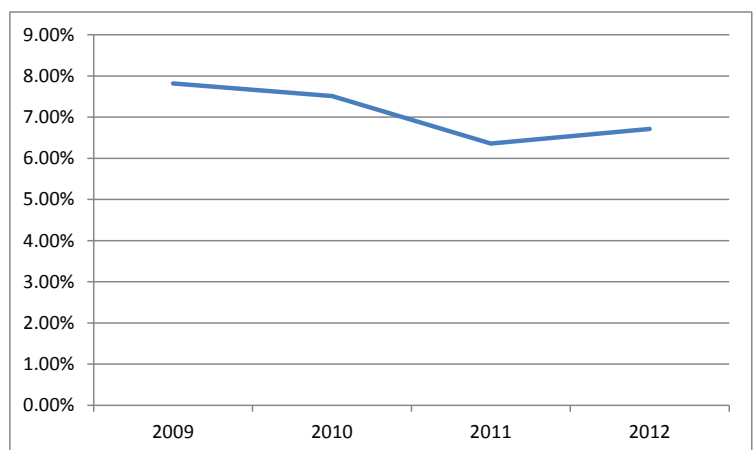

Figure 5. Percentage of firms with negative equity: 2009-2012 (source: own elaboration).

The amount of companies with negative equity decreased slightly between 2009 and 2011 and dropped significantly in 2012 (Fig. 4). The likeliest cause of bankruptcy seems to be a lack of funding; the other possible hypothesis, i.e. that the reduction is due to the recovery of the companies' equity through good business results, capital increases or similar seems to be less likely.

An analysis of the trend in negative equity companies in relative terms shows a worse path (Fig. 5): the average percentage of firms with negative equity tended to decrease during the early years of the crisis (2009-2011) but there was an upturn in 2012, precisely the year when the main decrease in absolute terms occurred. Between 2009 and 2011 the total number of companies grew gradually and moderately, while the number of firms with negative equity dropped at a similar pace. However, in 2012 the drop in the total number of bankrupt companies $(31.5 \%)$ was greater than that of companies with negative equity $(27.7 \%)$.

The volume of negative equity (Fig. 6) increased slightly during the first three years of the crisis, although the number of companies with negative equity was decreasing. Therefore the amount of negative equity assumed by each company was increasing. In 2012 the volume of negative equity suffered a particularly sharp decline of approximately $33 \%$, in line with the marked decrease in the number of companies. Nevertheless, this is not a par-

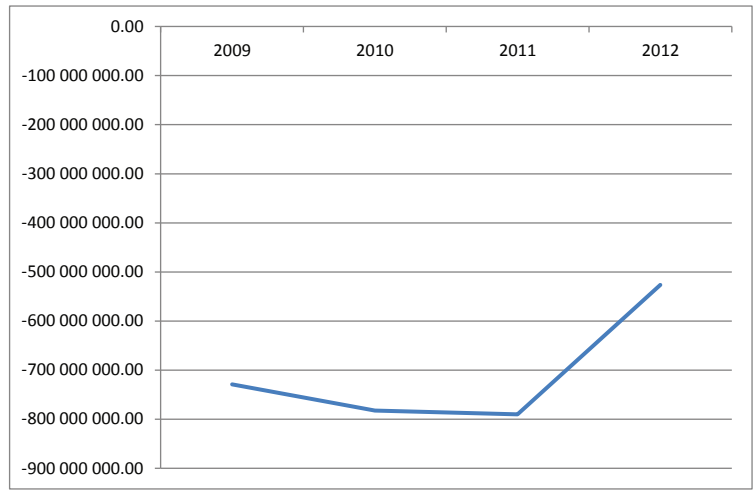

Figure 6. Volume of negative equity (in thousands): 2009-2012 (source: own elaboration). 
ticular feature of negative equity companies inasmuch as companies as a whole followed the same path $(32 \%$ of all companies reduced their equity that year).

Negative equity as a percentage of total equity (Fig. 7) underwent a significant, steady decline in the first three years, due not to the decline in the volume of negative equity but to the increase in total equity. In the fourth year it showed a tendency to stabilise: negative equity volume dropped, but by the same extent as non-negative equity.

Between 2009 and 2011 on average $6.8 \%$ of negative equity companies shut down, but the volume of negative equity increased by an average of $8.3 \% .2012$ cannot be considered as a benchmark year for the drop in negative equity because non-negative equity companies followed exactly the same path.

Based on the graphs above, it seems that the problem of negative equity in European companies has decreased during the crisis, giving the impression that not only is the current crisis not the cause of the problem, but that it has actually contributed to a relative improvement in the situation.

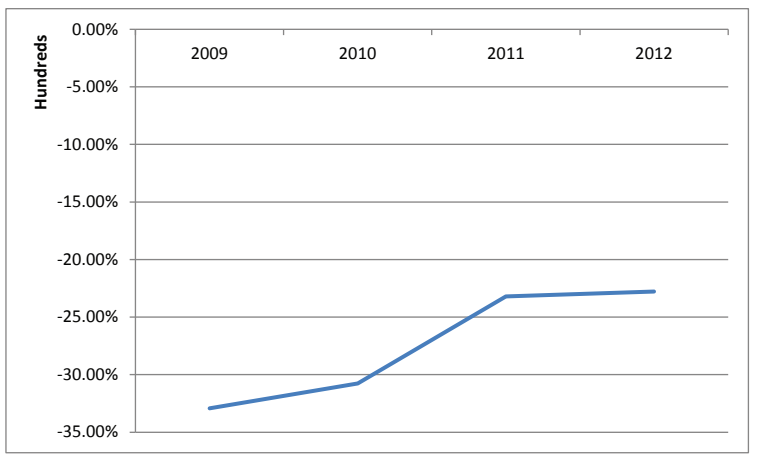

Figure 7. Volume of negative equity as a percentage: 20092012 (source: own elaboration).

\section{Conclusions}

Several important and interesting conclusions can be drawn from this study. The first is concerned with scale; not only the number of companies with negative equity but also the volume of that equity has a negative impact on the economy. More than one billion Euros are at stake: nearly $10 \%$ of European GDP. This is a potential problem that could be harmful in terms of both competitiveness and ethics. On the competitive side, a study of zombie companies in the Japanese economy has confirmed how much damage they can cause due to their low productivity in comparison with sectors where there are fewer such companies, and due to the fact that they hamper the entry of more efficient companies in some sectors. From an ethical viewpoint decision-making power is in the hands of shareholders or a third party designated by shareholders, but if the wrong decisions are made the consequences in the form of losses is borne by third parties. Negative equity companies therefore clearly incur moral hazard.
It can also be concluded that a small number of firms account for a large part of the total, in line with the Pareto principle: the $9 \%$ of large $\&$ medium-sized firms account for $88 \%$ of all negative equity. This suggests that European authorities should treat larger firms differently. All the small firms are unlikely to go into bankruptcy and close down simultaneously, so the impact on the economy of their doing so can be expected to be small, at least in individual terms and in terms of the risks transferred to third parties. However allowing a single large company to fail could result in serious harm to third parties, at least in terms of the volume of funds at risk and of the number of stakeholders involved. Measures to accompany all companies may be envisaged, but with special emphasis on the largest ones, because the impact of their fall could not easily be absorbed by society and it would thus be impossible to prevent serious harm in terms of both competitiveness and ethics.

Size is one potential determinant for the future analysis of negative equity companies, but other factors that might have been thought a priori to explain the behaviour of such companies are ruled out by this research. The country cluster used seems to show that neither culture nor geographical area is determinant in explaining the distributions of these companies from one country to another. For example the a priori assumption of a split between Latin and Anglo-Saxon or Southern countries vs. Nordic countries is not borne out in explaining the distribution of these companies around Europe. Another important factor that seems ex-ante to be a likely determinant of the behaviour of this type of firms is the crisis, but our analysis shows that it is not a conclusive determinant. This leads to the conclusion that the problem is not cyclical but structural. Thus, it is determined that these companies existed before the crisis and will continue to exist after its end.

Hence, there are potentially important implications for encouraging European commissions or decision makers to factor the situation of these companies into their policies, include them in economic models, monitor them (especially large companies) and take on board that the problem is not cultural or geographical but exists throughout Europe. It is very important to be aware that after the crisis the problem will continue, so it is necessary to be proactive to reduce the negative impact that these companies could potentially have on the economy and especially on the competitiveness of Europe. This might help to create concern in Europe for the risks assumed due to the lack of enforcement of law to establish and strengthen involvement practices regarding risks assumed by stakeholders without their awareness and hence without their approval.

The main measures that could be taken to reduce this moral hazard would, in our view, three types. First, once accounts are deposited and the company shows that the equity value is negative in book value in the commercial register, it should be necessary to officially supervise the annual accounts, forcing companies to start officially the bankruptcy process, if in the short term (three to six 
months) they have not been able to generate positive cash flow; it will be necessary to force companies to recapitalize, or if not possible force to start the liquidation. If we want to be more flexible, it will be an option to force to write a note in the annual accounts, where it is explain deeply this financial circumstance, moreover, it will be useful to force explicitly in any commercial contract reference to this question. It will affect company reputation, of course, but this information transparency would reduce moral hazard of stakeholders interested. Another line of action, which can be complementary, would focus on the liability of directors, so that in these cases clearly illegal in most EU countries. It will be to establish legally that managers and/or board directors should be "with solidarity" respond with their personal assets for company debts, at least as long as their obligation to capitalize or go to bankruptcy is breached. A third type of action, most original, it is to establish the rule to redistribute the company governance' rights among creditors, with the aim to align again risk, decision making and profit.

\section{Acknowledgements}

The authors are grateful to Oriol Amat, Eric Lamarque and John Boatrigh, and also referees for their insightful comments. This work is part of the research group ECRI Ethics in Finance and Social Value, and supported by UPV/EHU (GIU 15/10) and Basque Government research project (UFI 11/51).

\section{References}

Agle B, Agle L (2007) The stated objectives of the Fortune 500: examining the philosophical approaches that drive American largest firms, Working Paper. University of Pittsburgh.

Ahearne AG, Shinada N (2005) Zombie firms and economic stagnation in Japan, International Economics and Economic Policy 2(4): 363-381. https://doi.org/10.1007/s10368-005-0041-1

Allen F, Carletti E (2006) Credit risk transfer and contagion. Journal of Monetary Economics 53(1): 89-111. https://doi.org/10.1016/j. jmoneco.2005.10.004

Arrow KJ (1971) Political and economic evaluation of social effects and externalities. Frontiers of Quantitative Economics: Papers Invited for Presentation at the Econometric Society Winter Meetings, New York.

Bank for International Settlements (2003) Credit risk transfer. Committee on the Global Financial System. Basel, Switzerland.

Boatright JR (2013) Ethics in finance ( $3^{\text {rd }}$ edn). Blackwell, Malden.

Caballero R, Hoshi T, Kashyap AK (2008) Zombie lending and depressed restructuring in Japan. American Economic Review 98(5): 1943-1977. https://doi.org/10.1257/aer.98.5.1943

Coase RM (1937) The nature of the firm. Económica New Series 4(1): 386-405.

Demsetz H (1983) The structure of ownership and the theory of the firm. Journal of Law and Economics 26(2): 375-390. https://doi. org/10.1086/467041
Donaldson T, Preston L (1995) The stakeholder theory of the corporation: concepts, evidence, and implications. Academy of Management Review 20(1): 65-91.

Freeman E, Harrison JS, Wicks AC, Parmar BL, De Colle S (2010) Stakeholder Theory: the State of the Art. Cambridge University Press, Cambridge. https://doi.org/10.1017/CBO9780511815768

Freeman RE, Harrison JS, Wicks A (2008) Managing for Stakeholders: Survival, Reputation, and Success. Yale University Press, New Haven.

Freeman RE (1984) Strategic Management: a Stakeholder Approach. Cambridge University Press, Boston.

Friedman M (1962) Capitalism and Freedom. University of Chicago Press, Chicago.

Giles C (2013) Central banks face zombie nightmare. Financial Times January 8 .

Gupta V, Hanges PJ, Dorfman P (2002) Cultural clusters: methodology and findings. Journal of World Business 37(1): 11-15. https://doi. org/10.1016/S1090-9516(01)00070-0

Hendrikse GWJ (2003) Economics \& Management of Organizations. McGrawHill, London.

Jensen M, Meckling W (1976) Theory of the firm: managerial behaviour, agency costs, and ownership structure. Journal of Financial Economics 3: 305-360. https://doi.org/10.1016/0304-405X(76)90026-X

Jones T (1995) Instrumental stakeholder theory: a synthesis of ethics and economics. Academy of Management Review 20(2): 404-437.

Kald M, Nilsson F (2000) Performance measurement at Nordic companies. European Management Journal 18(1): 113-127. https://doi. org/10.1016/S0263-2373(99)00074-2

Kane EJ (2012) Gaps and Wishful Thinking in the Theory and Practice of Central-Bank Policymaking. Presentation to the $30^{\text {th }}$ SUERF Colloquium - States, Banks, and the Financing of the Economy, 6 September 2012, Switzerland.

Ketchen DJ, Shook CL (1996) The application of cluster analysis in strategy management research: an analysis and critique. Strategic Management Journal 17(6): 441-458. https://doi.org/10.1002/ (SICI)1097-0266(199606)17:6<441::AID-SMJ819>3.0.C,2-G

Krugman P (2009) The Return of Depression Economics and the Crisis of 2008. WW Norton \& Company, New York.

Luo Q, Li H, Zhang B (2015) Financing constraints and the cost of equity: evidence on the moral hazard of the controlling shareholder. International Review of Economics \& Finance 36: 99-106. https:// doi.org/10.1016/j.iref.2014.11.010

Mara Faccio M, Marchica MT, Mura R (2011) Large shareholder diversification and corporate risk-taking. The Review of Financial Studies 24(11): 3601-3641. https://doi.org/10.1093/rfs/hhr065

Mitchell RK, Agle B, Wood D (1997) Toward a stakeholder identification and salience: defining the principle of who and what really counts. Academy of Management Review 22(4): 853-886.

Mohrman MB, Stuerke PS (2014) Shareowners' equity at Campbell soup: how can equity be negative? Accounting Education: An International Journal 23(4): 386-405. https://doi.org/10.1080/096392 84.2014.910814

Papworth T (2013) The Trading Dead: the Zombie Firms Plaguing Britain's Economy, and What to do About Them. Adam Smith Research Trust, England.

Pauly MV (1974) Overinsurance and public provision of insurance: the roles of Moral Hazard and adverse selection. Quarterly Journal of Economics 88(1): 44-62. https://doi.org/10.2307/1881793 
Recio ML (2011) Los recursos empresariales intangibles para superar la crisis económica. Economistas 126: 272-276.

Retolaza JL, San-Jose L, Ruiz-Roqueñi M (2014) Ontological stakeholder view: an innovative proposition. Global Business Review 15(1): 25-36. https://doi.org/10.1177/0972150913515590

Retolaza JL, San-Jose L, Urionabarrenetxea S, Garcia-Merino D (2016) Linking the moral hazard and leverage in companies. Ramon Llull Journal of Applied Ethics 144(7): 143-166.

Rowell D, Connelly LB (2012) A history of the term "Moral Hazard". The Journal of Risk and Insurance 79(4): 1051-1075. https://doi. org/10.1111/j.1539-6975.2011.01448.x

Shleifer A, Vishny RW (1992) Liquidation values and debt capacity: a market equilibrium approach. The Journal of Finance 47(4): 1343-1366. https://doi.org/10.1111/j.1540-6261.1992.tb04661.x
Stewart I (2014) Zombie companies. Deloitte monday briefing. http:// www.deloitte.com/view/en_GB/uk/research-and-intelligence/monday-briefing/index.htm [cited 13 May 2014]

Stoney C, Winstanley D (2001) Stakeholding: confusion or utopia? Mapping the conceptual terrain. Journal of Management Studies 38(5): 603-626. https://doi.org/10.1111/1467-6486.00251

Wagner W, Marsh IW (2006) Credit risk transfer and financial sector stability. Journal of Financial Stability 2(2): 173-193. https://doi. org/10.1016/j.jfs.2005.11.001

Williamson OE (1967) Hierarchical control and optimum firm size. Journal of Political Economy 75(2): 123-138. https://doi.org/10.1086/259258 